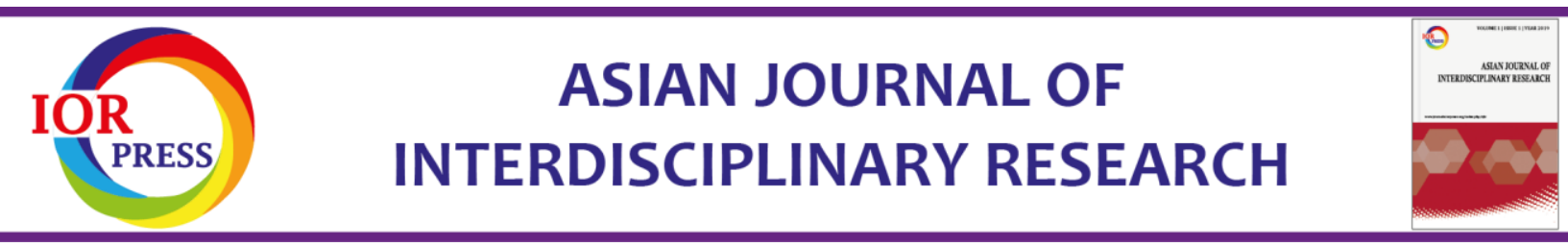

\title{
A Case Review Study of a Young Adult with Low-Functioning Autistic Disorder transitioning from School to Work
}

\section{Chong Lee WONG a, *}

a Registered Educational Therapist, Internet-Disability \& Disorder Diagnostics Clinic (i-DDDC), Singapore.

*Corresponding Author: willingspirit2000@yahoo.com.sg DOI: https://doi.org/10.34256/ajir2011

Received: 12-11-2019

Accepted: 01-02-2020

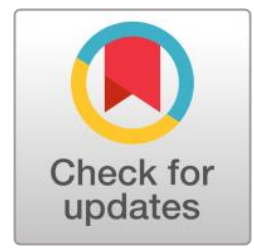

\begin{abstract}
The transition process from school to work is often challenging for young people, especially those with disabilities. In order to gather a meaningful transition, a cross battery assessment and a functional vocational evaluation are needed. In this case review study, a young adult aged 20 years 8 months, JC, had his autistic condition reviewed. Assessment was done so as to know the current status of JC's abilities and skills and his state of readiness for vocational employment. With the results, JC could then use them to look for vocational training centers so as to develop more skills in the area of his vocational interest.
\end{abstract}

Keywords: Autism, Vocational Assessments, Cross-Battery Assessments, Transition.

\section{Introduction}

Preparation for an adolescent's readiness in transition to the adult world is never an easy task. This is even more so for the case of people with special needs. According to Wong (2017), these Young Adults with Special Needs (YASN) face many challenges in the work environment. These YASN come with no prior working experience, difficulties completing work duties, poor communication, linguistic and social skills. To make matters worse, very few employers have a full picture or understanding of YASN's disabilities and hence, this can lead to a further obstacle for YASN in search for a job.

For the typically developing child growing into an adolescent, parents and educators would often either ask or guide them on their path to what and where they want to be in the future. However, for children with special needs, the question on "what do you want to be" or guiding the YASN is seldom asked. One good explanation is the limited options YASN either have or take whatever what are given to them without really being trained for the job itself.

Contrary to the common belief that there is no need to dream about their future job, our YASN deserve to have dreams for themselves so that eventually they can also contribute to the society. YASN have to be empowered or given the right to make their own decisions about where they will live, work and spend their leisure time (Wong, 2017). Parents, teachers and job coaches can support them to make a meaningful work life via proper vocational training from school to work. 


\section{Methods and Assessments}

As described above, the school-toworkplace transition (S2WT) is often a big challenge for the YASN. The choice of work and the preparation involves a mix of complex decisions. However, with proper planning, the path to find a suitable job can be made much easier when sufficient S2WT readiness is well prepared. For instance, the use of vocational assessment as a means to match YASN's abilities and preferences to suitable training programs can provide a useful way to ensure a smooth S2WT in the search for an appropriate job that matches the YASN's profile.

According to High (1991), vocational assessment is defined as a systematic ongoing process in which the assessment questions seek to help students find out their vocational preferences and potential. The assessment is carried out either before a student embarks in a specific program or during which the student is already in the program. Specifically, the assessment process entails observations, anecdotal information, on-the job-try-outs, classroom performances, tests and work samples. It is through the collection on the information that a profile of the student's interest, aptitudes, level of severity on the special needs, learning styles, work habits and behaviors, personal and social skills, work attitudes and self-concept are being established. Administering a battery assessment of tests serves to raise a YASN's self-awareness as well as a better understanding of his level of skills. Knowing the YASN's personal and vocational attributes, strengths and weakness help the him/her draft short and long-term career goals that are realistic. In this way, it ensures the constant employability of the YASN.

High (1991) stated the following three levels of vocational assessment. They are as follows:

- Level 1: Screening stage determines functional skills and establishing baseline of the student in terms of vocational planning. Collection of information is via interviewing, reviewing records or interest inventories.

- Level 2: Clinical or Exploratory stage will be needed if the student needs more information so as to develop his vocational profile and clarify vocational planning.

- Level 3: Vocational Evaluation stage involves more comprehensive assessment. The vocational evaluator conducts both informal assessments like situational assessments or on-the-jobs try-outs and formal assessments like standardized assessments and tests.

Apart from the abovementioned assessments, a YASN's self-concept should also be included as part of an essential component of a vocational assessment as the self-concept is critical to his/her educational and vocational functioning.

In the case of $\mathrm{JC}$, his parents gave their signed consent to conduct the vocational assessments since they were interested to know JC's vocational future, both in training and employment and to be able to make decisions that based on his interests, abilities as well as his potential.

\subsection{Level 1-Screening and Level 2- Clinical/Exploratory Assessment}

The cross-battery assessment (X-BA) is the process by which assessors use information from multiple test batteries to help guide in their diagnostic decisions and to gain a fuller picture of an individual's cognitive, conative, affective and sensory abilities and skills than can be ascertained through the use of multiple-battery assessments of the same block of abilities and skills or single-battery assessments (Flanagan \& McGrew, 1997). The cross-battery approach (X-BA) was first introduced in the late 1990s and offers practitioners the means to make systematic, valid and up-to-date interpretations of intelligence batteries and to 
augment them with other tests in a way that is consistent with the empirically supported Cattell-Horn-Carroll (CHC) theory of cognitive abilities (Flanagan, Ortiz, \& Alfonso, 2007).

A series of standardized tests and checklists were administered to provide an updated of JC's autistic condition. These tests follow the Hierarchy of Building Blocks of Abilities and Skills (see Chart 1 below) postulated by Chia (2008) as a framework for cross-battery assessment (X-BA for short).

\subsubsection{Block I-Innate Abilities \& Skills}

This is also known as the Foundation Block refers to the core block of an individual's innate abilities which deal with the use of language to communicate, abstract thoughts and reasoning skills, memory retention as well as problem solving skills. An example of an assessment tool for this level is an IQ test.

\section{Primary Measure: General Ability Measure for Adults (GAMA)}

The GAMA test was used to measure the general intelligence for the following purposes:
1. In counseling setting: An educational therapist, community care practitioner and/or job coach had to decide on the choice of intervention that was most consistent in helping JC's intellectual ability;

2. For career counseling: Lindenmann and Matarazzo (1990) stated that knowledge of intellectual ability is an important contribution to effective career counseling and the GAMA results can be used to facilitate vocational decisions; and/or

3. For business and industry: The GAMA test results were especially useful in an employment setting when evaluating JC in terms of his linguistic and educational background.

An individual's GAMA IQ test score is based on the four subtest scales scores. Using hand-scoring materials or computerized scoring, it can generate a graphic representation of an individual's total score with a 90\% confidence interval. An Ability Classification (from Well Below Average to Very Superior) and a Percentile rank are also reported. Subtest scores include a classification, a deviation score, and Strength/Weakness indications.

\begin{tabular}{lllll}
\hline $\begin{array}{c}\text { Hierarchy of } \\
\text { Blocks }\end{array}$ & Abilities \& Skills (A\&S) & $\begin{array}{c}\text { Primary } \\
\text { Measure } \\
\text { (PM) }\end{array}$ & $\begin{array}{c}\text { Supplementary } \\
\text { Measure (SM) }\end{array}$ & $\begin{array}{c}\text { Additional } \\
\text { Measure } \\
\text { (AM) }\end{array}$ \\
\hline Block 1 & Innate A\&S & GAMA & $\begin{array}{c}\text { TONI-3 } \\
\text { DaP-IQ }\end{array}$ \\
Block 2 & Sensory Perceptual-Motor & SP-CQ & -- & -- \\
& Behavioral A\&S & & & ARS-Q \\
& & & EHQ \\
Block 3 & Adaptive Behavioral A\&S & ABDS & -- & B-VAQ \\
Block 4 & Social-Emotional & GARS-2 & ESQ & AHfQ \\
& Behavioral A\&S & & & - \\
Block 5 & Cognitive Behavioral A\&S & CREVT-2 & -- & K-TDT \\
\hline
\end{tabular}

Chart 1. Hierarchy of Building Blocks of Abilities \& Skills 
Table PM1. Results of the GAMA

\begin{tabular}{lcccccc}
\hline \multicolumn{1}{c}{ Subtests } & $\begin{array}{c}\text { Raw } \\
\text { Score }\end{array}$ & $\begin{array}{c}\text { Scaled } \\
\text { Score }\end{array}$ & $\begin{array}{c}\text { Deviation } \\
\text { Score }\end{array}$ & $\begin{array}{c}\text { Value } \\
\text { needed } \\
\text { for Sig. }\end{array}$ & $\begin{array}{c}\text { Sig. } \\
\text { Yes/No }\end{array}$ & $\begin{array}{c}\text { Ability } \\
\text { Classification }\end{array}$ \\
\hline 1. Matching & 5 & 5 & 1 & 3.9 & No & Below Ave \\
2. Analogies & 3 & 4 & 0 & 3.4 & No & Below Ave \\
3. Sequences & 1 & 3 & -1 & 3.4 & No & Well Below Ave \\
4. Construction & 3 & 4 & 0 & 4.0 & No & Below Ave \\
\hline Total Scaled Score & & 16 & & & & Well Below Ave \\
Mean Score & & 4 & & & & \\
GAMA IQ Score & & 65 & & & & \\
95\% CI & & $60-77$ & & & & \\
Percentile Rank & & $1 \%$ ile & & & & \\
\hline
\end{tabular}

The GAMA test uses four types of test items and subscales:

(1) Matching: This subtest involves examining the shapes and colors of stimuli to determine which response option is identical.

(2) Sequences: This subtest requires the analysis of the interrelationships of designs as they move through space.

(3) Analogies: This subtest involves the discovery of the relationships in a pair of abstract figures and the recognition of similar conceptual relationships in a different pair of figures.

(4) Construction: This subtest involves the analysis, synthesis, and rotation of spatial designs to construct a new figure.

Based on the above tabulation, JC's GAMA IQ test score was based on the four subtest scaled scores. Using the hand-scoring materials, his total score was computed to provide a graphic representation of his general intellectual ability with a 95\% confidence interval. An Ability Classification (from Well Below Average to Very Superior) and a Percentile rank have been provided in Table
PM1 above. The subtest scores include a classification, a deviation score, and significant/insignificant or yes/no indications.

For all the four GAMA subtests, JC scored below average for Matching, Analogies and Construction subtests, and well below average for Sequences subtest. His GAMA IQ of 65 (well below average) was indicative of mild intellectual disability. With such an IQ (60-70), about $87 \%$ of those with an intellectual and developmental disability would be a little slower than normal in learning new information. A child with mild disability may not be evident or even diagnosed until s/he goes to school. Even if poor performance levels are recognized, it may take an expert to distinguish mild intellectual/cognitive disability from a learning disability or behavioral problem based on the assessment results. As the child becomes older, s/he is considered "slow" rather than "retarded" based on his/her progress. For most of them within this IQ range, they can still live independently, read, drive, cook, marry, raise children, etc.

A further supplementary assessment is recommended: Draw-a-Person Intellectual Ability Test for Children, Adolescents and 
Adults (DaP-IQ; Reynolds \& Hickman, 2004). This was the first among all the primary and supplementary measures to be administered. The reason for the DaP-IQ administration was to find out how JC was feeling about himself and the situation when he was having a stressful workplace experience during his attachment at the Dignity Kitchen. The DaP-IQ can also provide a better understanding if JC's negative workplace experience would affect his intellectual performance based on GAMA administration.

\section{Supplementary Measure: Test of Nonverbal Intelligence-3 ${ }^{\text {rd }}$ Edition (TONI-3)}

The Test of Nonverbal Intelligence- $3^{\text {rd }}$ Edition (TONI-3) is an individuallyadministered nonverbal test for ages 6-00 to 89-11, to assess aptitude, intelligence, abstract reasoning, and problem solving in a completely language-free format. There is one composite score, assessing level of nonverbal intellectual development-primarily fluid intelligence, abstract reasoning and problem solving. According to Siegel (1996), TONI-3 is recommended as part of the autism battery assessment "[T]o provide a basis for separating many of the effects of mental retardation (intellectual disability) from autism spectrum disorder" (p.17).

According to Sattler (2001), the mean score for cognitively disabled students bordered the established criteria cut-off ( $S S=70$ ), suggesting a number of examinees achieved scores higher than that.

The results of the TONI-3 assessment protocol, item \#18 was the last one JC got it correct before he made 3 consecutive mistakes, obtaining the raw score of 14 at Tscore of 34 and standard score of 76 at 5\%ile rank (poor intellectual/cognitive functioning). When JC was allowed to continue the test, he obtained another 7 correct responses with a total raw score of 21 at T-score of 39 and standard score of 84 at 14\%ile rank (below average). He gave the correct response to his last item \#40. JC exhibited the trainability potential but those (e.g., vocational trainer, job coach, workplace supervisor) working with him must understand his overall profile to maximize his full potential.

In other words, JC's condition remained within the category of borderline intellectual/cognitive functioning. Being trainable, JC should be given the opportunity to be trained for the vocational career that best matched his potential.

\section{Supplementary Measure: Draw-a-Person} Intellectual Ability Test for Children, Adolescents and Adults (DaP-IQ)

The Draw-A-Person Intellectual Ability Test for Children, Adolescents, and Adults (DAP-IQ; Reynolds \& Hickman, 2004) provides an objective scoring system that is applied to a standardized method for obtaining a drawing of a human figure, from which an IQ estimate is then derived. The test is untimed, but most examinees (children and adults) can complete the drawing in 5 minutes or less. The test may be administered individually or in groups, the latter being primarily for screening purposes.

Table SM1. Results of TONI-3

\begin{tabular}{cccccc}
\hline $\begin{array}{c}\text { Raw } \\
\text { Score }\end{array}$ & $\begin{array}{c}\text { T-score } \\
(\mathbf{M = 5 0} \\
\mathbf{S D = 1 0})\end{array}$ & $\begin{array}{c}\text { Standard } \\
\text { Score }\end{array}$ & $\begin{array}{c}\text { Percentile } \\
\text { Rank }\end{array}$ & $\begin{array}{c}\text { Age } \\
\text { Equivalent }\end{array}$ & Comments \\
\hline 14 & 34 & 76 & $5 \%$ ile & $7: 06$ & Cut-off ceiling at item \#18 \\
21 & 39 & 84 & $14 \%$ ile & $10: 03$ & Completing the entire test \\
\hline
\end{tabular}


Table SM2. Results of DaP-IQ

\begin{tabular}{lllll}
\hline DaP-IQ & Score & Mean & Standard Deviation & Yrs; Mths \\
\hline Raw Score & 11 & -- & -- & -- \\
Standard Score & 67 & 100 & 15 & -- \\
Percentile Rank & 1 & -- & -- & -- \\
T-Score & 28 & 50 & 10 & -- \\
z-Score & -2.20 & 0 & 1 & -- \\
Stanine & 1 & -- & -- & -- \\
Age Equivalent & -- & -- & -- & $5 ; 06$ \\
\hline
\end{tabular}

The DAP-IQ provides a common set of scoring criteria across its full age range of 4 years through 89 years and is the first draw-aperson projective test to do so. This not only eases the burden on the assessor but allows for more direct, continuous measurement of a common construct across the age range.

Based on the projective drawing technique of the DaP-IQ administration, JC drew two big stick figures about $18 \mathrm{~cm}$ long standing side by side. With a DaP-IQ of 67, i.e., below 70, JC was significantly impaired in his intellectual capacity and also considered cognitively immature.

In addition, JC also drew a house and a tree, in addition to drawing a person, based on the House-Tree-Person (H-T-P) Projective Drawing Technique (Buck, 1977), to understand his personality. This projective personality test - a type of measure in which JC can respond to or provide ambiguous, abstract, or unstructured stimuli, often in the form of pictures or drawings. It is suitable for anyone aged three and above.

The HTP-PDT was done to find out JC's emotional state of mind and/or personality through interpretation of his drawings and responses to a set of questions relating to the drawings. This projective drawing technique is also sometimes used as part of an assessment of brain damage or overall neurological functioning (Buck, 1977). The results from the
H-T-P administration could be used for counselling JC if needed. Only the Tree Drawing component of the HTP-PDT was used as an additional measure, i.e., Koch Tree Drawing Test (K-TDT), under the $4^{\text {th }}$ Building Block of Social-Emotional Behavioral Abilities \& Skills.

However, JC's H-T-P results did not constitute part of the 3-level Vocational Assessment (VA) process involving the following:

(1) Vocational screening (VS) of functional skills;

(2) Clinical or exploratory vocational measurement to develop his Vocational Profile (VP1) and to clarify his Vocational Planning (VP2); and

(3) Vocational Evaluation (VE) for job or workplace placement (National Information Center for Children \& Youth with Disabilities, 1990).

\subsubsection{Block II-Sensory Behavioral Abilities \& Skills}

Block II focuses on the sensoryperceptual-motor coordination and related behavioral skills and abilities involving balance/motion of the body (vestibular) and position of body (proprioception). An example 
of an assessment tool for this level is the Sensory Profile (Dunn, 1999).

\section{Primary Measure: Sensory Profile- Caregiver Questionnaire (SP-CQ)}

The Sensory Profile-Caregiver Questionnaire (SP-CQ; Dunn, 1999) measures the sensory processing on an individual's daily performance patterns by providing information about his/her tendencies to respond to stimuli and which sensory systems are likely contributing or creating barriers to functional performance. Results for this primary measure allowed both the assessors and the primary caregivers to better understand JC's sensory responses to external/internal stimuli. The SP-CQ contains some 125 items that are organized into three main sections (Dunn, 1999):

(1) Sensory Processing: It contains six item categories that measure an individual's responses to possessing of sensory inputs via auditory, visual, vestibular, tactile and oral processes;

(2) Modulation: It contains five item categories that measure the individual's ability to monitor and regulate information to generate an appropriate response to the situation; and

(3) Behavioral and Emotional Responses: It contains three item categories that measure children's emotional and behavioral responses to sensory experiences.

In the SP-CQ administration (completed by proxy), the primary caregivers (i.e., JC's mother and the family helper) were asked to record the frequency with which their charge displays each itemized behavior on a 5-point Likert scale: 1-always, 2-frequently, 3occasionally, 4-seldom, or 5-never.

The results obtained from the SP-CQ administration (completed by proxy) provided the assessors a means to understand JC's sensory processing patterns and their effects on his ability to perform daily activities like handling relationships, performing tasks as required by his school, responding to every day challenges and other every day activities.

As mentioned above, the caregiver questionnaire was completed by proxy involving his mother (the main caregiver) and his family helper (who also helped to care for JC). With the SP-CQ results, JC's SP profile based on threshold level to sensory-related processing, sensory modulation, and emotional-behavioral issues was obtained. The SP-CQ information was useful for designing an appropriate intervention/remediation plan for JC, taking into consideration his sensory needs.

JC's results for sensory processing were mainly typical. However, at the time of this SPCQ administration, JC showed "probable" problems in his sensory processing to endurance/tone, body position and movement. He also showed "probable" problems in his regulation of sensory input affecting his emotional responses and definite problems in his regulation of visual input affecting his emotional responses and activity level. In other words, JC might display intense vulnerability to the perception of being rejected, teased or criticized by people significant to him (e.g., those adults who have authority over him and what he did, e.g., teacher, job coach, workplace supervisor, etc.). His results from the SP-CQ section on Emotional and Behavioral Responses also indicated that JC showed "probable" problems in social/emotional responses as well as behavioral outcomes of sensory processing. It could be a condition of rejection sensitivity dysphoria (RSD), i.e., a sudden development of a mood disorder (Dodson, 2018, 2019). When the emotional response of RSD is externalized, it can look like a flash of rage or/and be mistaken for being aggressive, angry or poor in anger management (Dodson, 2018). 
Table PM2-A. Results of SP-CQ 14 Sections

\begin{tabular}{|c|c|c|c|c|c|c|c|}
\hline Section & Score & Descriptor & LT/HT & $\begin{array}{l}\text { Without } \\
\text { disabilities }\end{array}$ & ADHD & Autism & $\begin{array}{l}\text { With other } \\
\text { disabilities }\end{array}$ \\
\hline \multicolumn{8}{|c|}{ SENSORY PROCESSING (SP) } \\
\hline $\begin{array}{l}\text { A. Auditory } \\
\text { processing }\end{array}$ & $33 / 40$ & Typical & $\mathrm{HT} / \mathrm{I}$ & $\sqrt{ }$ & -- & -- & $\sqrt{ }$ \\
\hline B. Visual processing & $41 / 45$ & Typical & $\mathrm{HT} / \mathrm{I}$ & $\sqrt{ }$ & -- & -- & -- \\
\hline $\begin{array}{l}\text { C. Vestibular } \\
\text { processing }\end{array}$ & $48 / 55$ & Typical & $\mathrm{HT} / \mathrm{I}$ & $\sqrt{ }$ & $\sqrt{ }$ & -- & $\sqrt{ }$ \\
\hline D. Touch processing & $77 / 90$ & Typical & $\mathrm{HT} / \mathrm{I}$ & $\sqrt{ }$ & -- & -- & $\sqrt{ }$ \\
\hline $\begin{array}{l}\text { E. Multisensory } \\
\text { processing }\end{array}$ & $30 / 35$ & Typical & $\mathrm{LT} / \mathrm{I}$ & $\sqrt{ }$ & -- & -- & $\sqrt{ }$ \\
\hline $\begin{array}{l}\text { F. Oral sensory } \\
\text { processing }\end{array}$ & $48 / 60$ & Typical & $\mathrm{HT} / \mathrm{I}$ & $\sqrt{ }$ & $\sqrt{ }$ & $\sqrt{ }$ & $\sqrt{ }$ \\
\hline \multicolumn{8}{|l|}{ MODULATION (MOD) } \\
\hline $\begin{array}{ll}\text { G. SP related to } \\
\text { endurance/tone }\end{array}$ & $38 / 45$ & Probable & Note & & $\sqrt{ }$ & $\sqrt{ }$ & $\sqrt{ }$ \\
\hline $\begin{array}{l}\text { H. Modulation related } \\
\text { to body position \& } \\
\text { movement }\end{array}$ & $40 / 50$ & Probable & Note & $\sqrt{ }$ & $\sqrt{ }$ & $\sqrt{ }$ & $\sqrt{ }$ \\
\hline $\begin{array}{l}\text { I. Modulation of } \\
\text { movement } \\
\text { affecting activity } \\
\text { level }\end{array}$ & $25 / 35$ & Typical & $\mathrm{HT} / \mathrm{I}$ & $\sqrt{ }$ & $\sqrt{ }$ & $\sqrt{ }$ & $\sqrt{ }$ \\
\hline 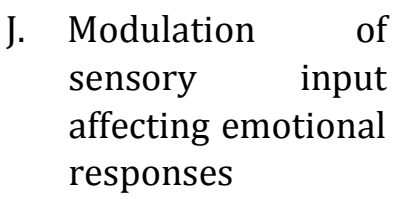 & $15 / 20$ & Probable & $\mathrm{HT} / \mathrm{I}$ & $\sqrt{ }$ & $\sqrt{ }$ & $\sqrt{ }$ & $\sqrt{ }$ \\
\hline $\begin{array}{ll}\text { K. } & \text { Modulation of } \\
\text { visual input } \\
\text { affecting emotional } \\
\text { responses \& } \\
\text { activity level } \\
\end{array}$ & $10 / 20$ & Definite & $\mathrm{LT} / \mathrm{I}$ & -- & $\sqrt{ }$ & $\sqrt{ }$ & $\sqrt{ }$ \\
\hline \multicolumn{8}{|c|}{ BEHAVIOR \& EMOTIONAL RESPONSES (BER) } \\
\hline $\begin{array}{l}\text { L. Emotional/Social } \\
\text { Responses }\end{array}$ & $59 / 85$ & Probable & -- & -- & $\sqrt{ }$ & $\sqrt{ }$ & $\sqrt{ }$ \\
\hline $\begin{array}{l}\text { M. Behavioral } \\
\text { outcomes of SP }\end{array}$ & $20 / 30$ & Probable & Note & -- & $\sqrt{ }$ & $\sqrt{ }$ & $\sqrt{ }$ \\
\hline $\begin{array}{ll}\text { N. } & \text { Items indicating } \\
\text { thresholds for } \\
\text { response }\end{array}$ & $12 / 15$ & Typical & Note & $\sqrt{ }$ & $\sqrt{ }$ & $\sqrt{ }$ & $\sqrt{ }$ \\
\hline Scores & & & & $10 / 14$ & $10 / 14$ & $9 / 14$ & $13 / 14$ \\
\hline Percentage & & & & $71.4 \%$ & $71.4 \%$ & $64.3 \%$ & $92.9 \%$ \\
\hline
\end{tabular}

Key:

LT=Low Threshold which indicates sensory sensitivity or/and sensory avoiding patterns of performance LT/I=Inclination to/preference for Low Threshold but disinclination to High Threshold HT=High Threshold which indicates poor registration or/and sensory seeking patterns of performance HT/I=Inclination to/preference for High Threshold but disinclination to Low Threshold 
Table AM1. Results of RSDS

\begin{tabular}{ccccc}
\hline & \multicolumn{3}{c}{ Scores } \\
Number of Items & Often & Not Often & Yes & No \\
\cline { 2 - 4 } Items $1,2,3,4,5,6,7,8,9,10,12,13$ and \\
15 & 2 & 11 & -- \\
\hline Items $11 \& 14$ & -- & -- & 0 & 2 \\
\hline
\end{tabular}

Results of RSDS: Rejection sensitivity dysphoria can be ruled out in JC's case.

\section{Table PM2-B. Results of SP-CQ 9 Factors}

\begin{tabular}{lllllll}
\hline Factor & Score & Descriptor & $\begin{array}{l}\text { Without } \\
\text { disabilities }\end{array}$ & ADHD & Autism & $\begin{array}{l}\text { With other } \\
\text { disabilities }\end{array}$ \\
\hline 1. Sensory Seeking & $65 / 85$ & Typical & $\sqrt{ }$ & $\sqrt{ }$ & $\sqrt{ }$ & $\sqrt{ }$ \\
2. Emotionally Reactive & $55 / 80$ & Probable & & $\sqrt{ }$ & & $\sqrt{ }$ \\
3. Low Endurance/Tone & $36 / 45$ & Probable & & $\sqrt{ }$ & $\sqrt{ }$ & $\sqrt{ }$ \\
4. Oral Sensory Sensitivity & $34 / 45$ & Typical & $\sqrt{ }$ & $\sqrt{ }$ & $\sqrt{ }$ & $\sqrt{ }$ \\
5. Inattention/Distractibility & $28 / 35$ & Typical & $\sqrt{ }$ & & & \\
6. Poor Registration & $31 / 40$ & Probable & & $\sqrt{ }$ & $\sqrt{ }$ & $\sqrt{ }$ \\
7. Sensory Sensitivity & $17 / 20$ & Typical & $\sqrt{ }$ & $\sqrt{ }$ & $\sqrt{ }$ & $\sqrt{ }$ \\
8. Sedentary & $16 / 20$ & Typical & $\sqrt{ }$ & $\sqrt{ }$ & $\sqrt{ }$ & $\sqrt{ }$ \\
9. Fine Motor/Perceptual & $14 / 15$ & Typical & $\sqrt{ }$ & & & \\
\hline Score & & & $6 / 9$ & $7 / 9$ & $6 / 9$ & $7 / 9$ \\
\hline Percentage & & & $67 \%$ & $78 \%$ & $67 \%$ & $78 \%$ \\
\hline
\end{tabular}

Hence, it is important to take note of the sudden change of mood or anger and to find out what has triggered it.

\section{Additional Measure: Rejection Sensitivity Dysphoria Screener}

The Rejection Sensitivity Dysphoria Screener (RSDS; Dodson, 2019) was administered as an additional measure/assessment to find out whether JC has any intense emotional response possibility caused by his perceptual to the surrounding people with whom he had encountered. The RSDS results are shown in Table SA1 below.
According to Ermer and Dunn (1998), sensory behavior of children with ADHD scored "probable" or "definite" likelihood on Factors 1, 2 and 5. "Factor 5 contains seven items describing inattention and distractibility. Although these behaviors are seen in a variety of disability categories, the disability best represented by these characteristics is ADHD". However, of the three factors, JC scored "probable" for Factor 2 and typical for Factors 1 and 5. In other words, he displayed emotional reactivity (Factor \#2), and this condition could be related to emotional hyperarousal (Dodson, 2019). Emotional hyperarousal is common among children and 
adults with ADHD - but its symptoms of intense, quickly shifting emotions are rarely recognized by clinicians or included in diagnostic tests. "The vast majority of individuals with ADHD instead experience hyperactivity as an internal feeling of hyperarousal - they can't turn off their whirring, overactive brains. This symptom often manifests as extreme emotions, a condition known as emotional hyperarousal" (Dodson, 2019, para.2).

\section{Additional Measure: Emotional Hyperarousal Questionnaire}

An additional measure/assessment was recommended to confirm the condition: Emotional Hyperarousal Questionnaire (EHQ; Dodson, 2018, 2019). Most clinicians are trained to recognize the intense emotions that come with mood disorders, yet they are wholly unfamiliar with the emotional symptoms of ADHD - particularly emotional hyperarousal. It was administered by proxy (with the family helper) on 15 June 2019. Below is Table SA2 that shows the results of EHQ:

Although the EHQ results are used to indicate that the physical hyperactivity was so often associated with attention deficit disorder (ADHD or ADD) - jumping on the couch, barreling across the playground, or talking without a pause for 10 minutes straight - is far from universal. In fact, this external symptom occurs in only one quarter of children and $5 \%$ of adults with the condition.
The vast majority of people with ADHD instead experience hyperactivity as an internal feeling of hyperarousal - they cannot turn off their whirring, overactive brains. This symptom often manifests as extreme emotions, a condition known as emotional hyperarousal.

People with emotional hyperarousal have passionate thoughts, reactions, and feelings that are more intense than those of the average person. In other words, their highs are higher and their lows are lower - which means people with ADHD often experience both happiness and criticism more powerfully than everyone else. This can make them appear overly sensitive and be off-putting to those around them - which, in turn, can do deep, long-term damage to their self-esteem.

However, in JC's case, like the rejection sensitivity dysphoria, the emotional hyperarousal could also be ruled out.

There was also a high possibility that JC might also manifest alexithymia, which "is characterized by difficulties in identifying, describing, and processing his own feelings, often marked by a lack of understanding of the feelings of others, and difficulty distinguishing between feelings and the bodily sensations of emotional arousal" (Wilkinson, 2019, para.3). It is especially important to note that alexithymia does not constitute a clinical diagnosis and is best conceptualized as a dimensional personality trait that is normally distributed in the general population (estimates of 10\%).

Table AM2. Results of EHQ

\begin{tabular}{cccccc}
\hline $\begin{array}{c}\text { Number of } \\
\text { Items }\end{array}$ & \multicolumn{2}{c}{ Score } & \multicolumn{2}{c}{ Score for Items 11 \& 14 } & Remarks: \\
\hline$\bullet$ & 15 items & 3 & 12 & -- & Not \\
often & Yes & -- & No evidence of emotional \\
hyperarousal.
\end{tabular}


Table AM3-A. Results of B-VAQ

\begin{tabular}{lcccl}
\hline \multicolumn{1}{c}{ Factors } & $\begin{array}{c}\text { Raw } \\
\text { Score }\end{array}$ & Percentage & Priority & \multicolumn{1}{c}{ Remark } \\
\hline Verbalizing (Vb) & $24 / 40$ & $60 \%$ & 2 & $\begin{array}{l}\text { Difficulty in communicating his } \\
\text { emotional reactions }\end{array}$ \\
Fantasizing (Fn) & $19 / 40$ & $47.5 \%$ & 3 & Borderline difficulty in imagining \\
Identifying (Id) & $16 / 40$ & $40 \%$ & 4 & No issue in identifying emotions \\
Emotionalizing (Em) & $25 / 40$ & $62.5 \%$ & 1 & Problem in emotionalizing \\
Analyzing (An) & $24 / 40$ & $60 \%$ & 2 & $\begin{array}{l}\text { Difficulty in explaining his } \\
\text { emotional reactions }\end{array}$ \\
\hline
\end{tabular}

Table AM3-B. B-VAQ Order of Factors

\begin{tabular}{cccc}
\hline Higher order factors & JC's B-VAQ & Cognitive Alexithymia & Affective Alexithymia \\
\hline 1 & $\mathrm{Em}$ & $\mathrm{Vb}$ & $\mathrm{Fn}$ \\
2 & $\mathrm{Vb}, \mathrm{An}$ & $\mathrm{Id}$ & $\mathrm{Em}$ \\
3 & $\mathrm{Fn}$ & $\mathrm{An}$ & -- \\
4 & $\mathrm{Id}$ & -- & -- \\
\hline
\end{tabular}

\section{Additional Measure: Bermond-Vorst Alexithymia Questionnaire (B-VAQ)}

An additional measure/assessment was recommended to confirm the condition: Bermond-Vorst Alexithymia Questionnaire (BVAQ; Bermond, Vorst, Vingerhoets, \& Gerritsen (1999). It was administered on 15 June, 2019.

There are five factors in the B-VAQ and they are: (a) "Verbalizing": the degree to which one is able or inclined to describe or communicate one's emotional reactions; (b) "Fantasizing": the degree to which one is inclined to fantasize, imagine, daydream, etc.; (c) "Identifying": the degree to which one can identify one's own emotions or arousal states; (d) "Emotionalizing": the degree to which one can be mentally and emotionally aroused by emotion-inducing events, and (e) "Analyzing": the degree to which one seeks cognitive explanations of own emotional reactions (see Tables AM3-A and AM3-B).
In Table AM3-A above, JC's highest scores in B-VAQ were found in Em (62.5\%), Vb (60\%) and An (also 60\%). There was no problem with Fn (47.5\%) and Id (40\%) since their respective scores in percentage were below $50 \%$.

There are two types of alexithymia: (a) cognitive alexithymia domain whose higherorder factors in the sequence from highest to lowest score: $\mathrm{Vb}$, Id \& An; and (b) affective alexithymia domain whose higher-order factors are in the following sequence: Fn \& Em (see Table AM3-B).

JC's B-VAQ profile did not meet both the cognitive and affective alexithymia domains. As a result, alexithymia could be ruled out in JC's case.

Returning to the SP-CQ 9 Factors, JC scored "probable" on Factors 2, 3 and 6, i.e., Emotionally Reactive, Low Endurance/Tone, and Poor Registration. These results mean that (i) JC displayed probability of emotional 
hyperarousal for Factor 2; (ii) JC's low endurance/tone for Factor \#3 indicated the probability of lacking supportive muscle tone, usually with increase mobility at the joints and may appear to display awkward movement patterns and poor ability to act in a sustained state of alert performance, causing problems in his movement kinematics, which indirectly also affects his social cognition (Cook, 2016), which focuses on how he processes, stores, and applies information about other people and social situations; in other words, social cognition focuses on the role that cognitive processes play in social interactions (Park et al., 2015); and (iii) JC displayed the probability of poor sensory registration (also known as hypo-sensitivity) for Factor \#6, i.e., applied "to those who do not absorb, or register, all of the input entering their body, and they are therefore 'missing out' on crucial information from their own body and the environment, which is used to make adaptive responses and learn" (Langer, 2019, para.2).

During the process of interviewing JC's mother as well as the family helper with the use of the SP-CQ, JC was described as an individual who could stay on-task and must finish the given task before he could move to the next. This is the condition of attentional hyperfocus (AHf), which has been defined as "[A] state of heightened, intense focus of any duration, which most likely occurs during activities related to one's school, hobbies, or "screen time" (i.e., television, computer use, etc.); this state may include the following qualities: timelessness, failure to attend to the world, ignoring personal needs, difficulty stopping and switching tasks, feelings of total engrossment in the task, and feeling 'stuck' on small details".

\section{Additional Measure: Adult Hyperfocus Questionnaire (AHfQ)}

An additional measure/assessment was recommended to confirm the condition: Adult Hyperfocus Questionnaire. However, as the test instrument was not available at that time, it was not carried out.

\subsubsection{Block III-Adaptive Behavioral Abilities \& Skills}

Block III concerns the adaptive behavioral skills and abilities, such as activities of daily living, social interaction, communication, self-help skills (e.g., toileting, dressing, bathing), personal hygiene and other related practical skills. An example of an assessment tool for this level is the Adaptive behavior Diagnostic Scale.

\section{Primary Measure: Adaptive Behavior Diagnostic Scale (ABDS)}

The Adaptive Behavior Diagnostic Scale is "an interview-based rating scale that is used to assess adaptive behavior of individuals for ages 2 through 21 years ... [Its] function ... is to establish the presence and magnitude of adaptive behavior deficits" (Pearson, Patton, \& Mruzek, 2016, p.1).

The results of the ABDS administration provides both the therapist working with the client and the client's parents a better understanding of the client's daily functionality, especially relating to the practical tasks under the category of Daily Living Skills (Bal, 2015).

The ABDS provides information on the following three domains or adaptive behavior subtests (Pearson, Patton, \& Mruzek, 2016):

(1) Conceptual Domain: It measures skills in language, reading, writing, mathematics, reasoning, knowledge, and memory.

(2) Social Domain: It measures empathy, social judgment, gullibility, communication skills, the ability to make and retain friendships, and similar interpersonal capabilities.

(3) Practical Domain: It measures selfmanagement personal care, home living, community use, job responsibilities, money 
management, recreation, and organizing school and work tasks.

Raw scores obtained in the ABDS administration are converted into domain index scores, percentile ranks and age equivalents. An adaptive behavior composite (ABC) index score is computed from the sum of the scores obtained from the three domains (see Table 7 below).

JC's ABC was at the extremely low functioning level with a raw score of 128 or an index score of 35 (at $<1 \%$ ile rank; SEM=3). Among the three adaptive behavioral domains, he scored worse in the social domain (SD) with a raw score of 71 or index score of 40 (at $<1 \%$ ile rank; SEM=4), which measures empathy, social judgment, gullibility, communication skills, the ability to make and retain friendships, and similar interpersonal capabilities. In other words, the child displayed problems in socialization at the time of assessment. The same problem in social domain has been found to in children with Intellectual Disability (ID) as well as those with Autism Spectrum Disorder (ASD) (Saulnier \& Klaiman, 2018).

Like the social domain (SD), JC's conceptual domain (CD), which measures skills in language, reading, writing, mathematics, reasoning, knowledge, and memory,wais also at the extremely low functioning level with a raw score of 98 and an index score of 40 (at <1\%ile rank; SEM=4).
Similarly, JC's practical domain (PD), which measures self-management personal care, home living, community use, job responsibilities, money management, recreation, and organizing school and work tasks, was also at the extremely low functioning level with a raw score of 94 and an index score of 48 (at <1\%ile rank; SEM=4).

JC's ABDS pattern was PD > CD > SD with PD being the best performance and SD being the worst. It sat nicely in the autism profile of adaptive behavior (Saulnier \& Klaiman, 2018).

\subsubsection{Block IV-Socio-Emotional Behavioral Abilities \& Skills}

Block IV consists of socio-emotional behavioral skills and abilities which cover adaptive, internalizing and externalizing behavioral skills. This level of skills and abilities can also be determined by assessment tools such as Sensory Profile (Dunn, 1999) done at level \#2.

Primary Measure: Gilliam Autism Rating Scale-2 ${ }^{\text {nd }}$ Edition (GARS-2)

The Gilliam Autism Rating Scale-2nd Edition (GARS-2; Gilliam, 2006) is used to identify a child with autism from those with other severe behavioral problems.

Table PM3. Results of ABDS

\begin{tabular}{ccccccc}
\hline Subscales & $\begin{array}{c}\text { Raw } \\
\text { Score }\end{array}$ & $\begin{array}{c}\text { Index } \\
\text { Score }\end{array}$ & SEM & $\begin{array}{c}\text { \%ile } \\
\text { Rank }\end{array}$ & Descriptor & $\begin{array}{c}\text { Age } \\
\text { Equiv. }\end{array}$ \\
\hline Conceptual domain & 98 & 40 & 4 & $<1 \%$ ile & ELF* & $5: 03$ \\
Social domain & 71 & 40 & 4 & $<1 \%$ ile & ELF & $2: 00$ \\
Practical domain & 94 & 48 & 4 & $<1 \%$ ile & ELF & $2: 11$ \\
\hline Adaptive Behavior & 128 & 35 & 3 & $<1 \%$ ile & ELF & -- \\
Composite (ABC) & & & & & & \\
\hline
\end{tabular}




\begin{tabular}{cccccc}
\hline Subtests & $\begin{array}{c}\text { Raw } \\
\text { Score }\end{array}$ & $\begin{array}{c}\text { Standard } \\
\text { Score }\end{array}$ & $\begin{array}{c}\text { Percentile } \\
\text { Rank }\end{array}$ & SEM & Descriptor \\
\hline $\begin{array}{c}\text { Stereotyped Behavior } \\
\text { (SB) }\end{array}$ & 9 & 6 & $9 \%$ ile & 1 & $\begin{array}{c}\text { Below } \\
\text { Average }\end{array}$ \\
Communication (COM) & 30 & 14 & $91 \%$ ile & 1 & $\begin{array}{c}\text { Average } \\
\text { Below } \\
\text { Social Interaction (SI) }\end{array}$ \\
\hline Sum of standard scores & 30 & $50 \%$ ile & 1 & Average \\
\hline Autism Quotient (AQ) & 100 & -- & -- & Below \\
\end{tabular}

It is based on the definition of autism adopted by the Autism Society of America (1994) and the diagnostic criteria for autistic disorder published in the Diagnostic and Statistical Manual of Mental Disorders. According to Gilliam (2006), "[A]t the time of its publication, the GARS was the only test of its kind normed on children who were known to have autism and was also most statistically reliable and valid standardized test for identifying children with autism" (p. v).

A note of caution to be taken here is that the GARS-2 scores alone do not diagnose anything, but they simply provide data about some characteristic(s) thought to be important in classifying autistic traits according to the triad of impairments in ASD. Therefore, the GARS-2 results should never be the single source of information used to diagnose autism. With the data about autistic behaviors that the GARS-2 provides, the GARS norms are used in comparing JC's scores with those of the US national sample of persons with autism.

"Autism spectrum disorder (ASD) is a neurodevelopmental condition characterized by impairment in (i) reciprocal social interaction and communication and (ii) restricted and/or repetitive behaviors or interests" (Wilkinson, 2019, para.1). JC's standard score for Autism Index (AI) of 100 (at $50 \%$ ile rank; SEM=4) placed him in the "Very Likely" category under the Probability of
Autism. According to Gilliam (2006), 34\% of the normative sample had AI scores in the range of 85 (at 16\%ile rank) and 100 (at $50 \%$ ile rank). The autistic subjects in the normative sample scored an average subscale standard score of 10 across all the three subtests, i.e., SB, COM and SI, with a mean AI of 100, while those who were multi-disabled scored an average subscale standard score of 6 across all the three subtests with a mean AI of 76. The GARS-2 subtest standard scores of 7 or higher have an Autism Index of 85 or higher are in the Very Likely category of autism. JC's results put him in the diagnostic groups of multi-disabled and autistic.

In terms of the three subtests, JC scored worst for Communication (COM) with a standard score of 14 (at 91\%ile rank; SEM=1), followed by Social Interaction (SI) with a standard score of 6 (at $50 \%$ ile rank; SEM=1) and least of all, Stereotyped Behavior (SB) with a standard score of 6 (at 9\%ile rank; SEM=1). The GARS-2 autism pattern was COM $>\mathrm{SI}>\mathrm{SB}$ with COM being the most severe and $\mathrm{SB}$ being the least severe. Because of his poor communication ability, he was unable to socialize well or adequately with others and might encounter problems in interacting with his peers or significant others, who did not understand his condition or personality.

Poor communication and social interaction (also noted in the abovementioned 
ABDS results) could also be the result of poor executive functioning skills that are affecting cognitive, behavioral and emotional processes. These symptoms constitute what is known as dysexecutive syndrome (ICD-10 Diagnostic Code: F07) - though a controversial term, also known as frontal lobe syndrome - was introduced by Baddeley and Wilson (1988) to describe a common pattern of dysfunction in executive functions, such as planning, abstract thinking, flexibility and behavioral control. It has been hypothesized that the working memory and central executive are impaired in this condition (Wilson, Evans, Emslie, Alderman, \& Burgess, 1998). As a result, there is also a need to determine if JC does have executive function deficits.

A further supplementary assessment was recommended to confirm the condition: Executive Skills Questionnaire. This was eventually administered as the assessors felt the results would be useful to better understand JC's condition.

\section{Supplementary Measure: Executive Skills Questionnaire (ESQ)}

The ESQ was developed to find out about an individual's performance in the executive skills, which include the following 12 subscales:

1. Response Inhibition: This is the capacity to think before one takes an action, and it is this ability to resist the urge to say or do something that allows the person the time to evaluate a situation and how his behavior might impact it.

2. Working Memory: This is the ability to hold information in memory while performing complex tasks. It incorporates the ability to draw on past learning or experience to apply to the situation at hand or to project into the future.

3. Emotional Control: This is the ability to manage emotions in order to achieve goals, complete tasks, or control and direct behavior.

4. Sustained Attention: This is the capacity to maintain attention to a situation or task in spite of distractibility, fatigue or boredom.

5. Task Initiation: This is the ability to begin projects without undue procrastination, in an efficient or timely fashion.

6. Planning/Prioritization: This is the ability to create a roadmap to reach a goal or to complete a task. It also involves being able to make decisions about what is important to focus on and what is not important.

7. Organization: This is the ability to create and maintain systems to keep track of information or materials.

8. Time Management: This is the capacity to estimate how much time one has, how to allocate it, and how to stay within time limits and deadlines. It also involves a sense that time is important.

9. Goal-directed Persistence: This is the capacity to have a goal, follow through to the completion of the goal, and not to be put off or distracted by competing interests.

10. Flexibility: This is the ability to revise plans in the face of obstacles, setbacks, new information or mistakes.

11. Metacognition: This is the ability to take a stand back to get a bird's eye-view of oneself in a situation. It is an ability to observe how one can problem-solve and it includes self-monitoring and selfevaluative skills.

12. Stress Tolerance: This is the ability to thrive in stressful situations and to cope with uncertainty, change, and performance demands.

Each subscale consists of 3 items based on the 7-point Likert rating scale. The maximum score is 21 and the minimum is 1 . The score range between 1-7 is in the poor or 
weak category; the score range between 8-14 is in the average category; and the score range between $15-21$ is in the good or strong category. The cut-off score is 10.5. Hence, scores between 8-10.5 are considered low average while scores between 10.5-12 are regarded as above average.

This measure was completed by JC's mother. JC's obvious strength could be found in his working memory and task initiation. His lowest score was in the metacognition. Four executive skills (i.e., planning/prioritization, flexibility, metacognition, and stress tolerance were in low average range. Five executive skills (i.e., emotional control, sustained attention, organization, time management, and goal-directed persistence) were in the above average range.

Generally, any score that is below the cut-off score of 10.5 is considered weak. In other words, metacognition, planning/ prioritization, flexibility and stress tolerance are the weaker executive skills. Each of them is briefly elaborated below:
1. Metacognition: Ability to stand back and evaluate how you are doing (can also be thought of as "self-monitoring" abilities). Poor or weak metacognition means an individual can make "careless" errors; does not check work before handing it in; does not stop to evaluate how things are going in the middle of a task or activity; thinks a task was well done, when in fact it was done poorly; thinks a task was poorly done, when in fact it was done well.

2. Planning: Ability to list steps needed to reach a goal or complete a task. Poor or weak planning means the individual does not know where to start when given large assignments; easily overwhelmed by task demands; difficulty developing a plan for long-term projects; problem-solving strategies are very limited and haphazard; starts working before adequately considering the demands of a task; and difficulty listing steps required to complete a task.

\section{Table SM3. Results of ESQ}

\begin{tabular}{cccccc}
\hline Executive Skills & Score & Strong/Weak & Executive Skills & Score & Strong/Weak \\
\hline Response inhibition & 0 & NA & Working memory & 18 & Strong \\
Emotional control & 12 & $\begin{array}{c}\text { Above } \\
\text { average }\end{array}$ & Task initiation & 15 & Strong \\
Sustained attention & 14 & $\begin{array}{c}\text { Above } \\
\text { average }\end{array}$ & Planning/prioritization & 10 & Low average \\
Organization & 13 & $\begin{array}{c}\text { Above } \\
\text { average } \\
\text { Flexibility }\end{array}$ & Time management & 14 & $\begin{array}{c}\text { Above } \\
\text { average }\end{array}$ \\
$\begin{array}{c}\text { Goal-directed } \\
\text { persistence }\end{array}$ & 12 & $\begin{array}{c}\text { Above } \\
\text { average }\end{array}$ & Stress tolerance & 10 & Low average \\
\end{tabular}

3. Flexibility: Ability to change focus, adapt to changing conditions or revise plans in the face of obstacles, new information or mistakes (can also be considered as "adaptability"). Poor or weak flexibility means slow to stop one activity and begin another after being instructed to do so; tendency to stay with one plan or strategy 
even after it is shown to be ineffective; rigid adherence to routines; and refusal to consider new information.

4. Stress tolerance: Ability to do a given task appropriately with minimal anxiety level. Poor or weak stress tolerance means an individual is struggling to cope with anxiety and stress and that triggers the fight, flight or freeze response. In other words, the individual is primed for aggression, withdrawal or paralysis.

\section{Additional Measure: Koch Tree Drawing Test (K-TDT)}

According to Garofalo (2008), tree is a metaphor to assess a drawer's personality, especially as a reflection of the drawer's interaction with his/her environment (see Crain, 2015, for detail). It was administered as an additional measure to find out JC's socialemotional state of mind since he is unable to express his feelings. The results of K-TDT are shown in Table AM4 below:

The interpretive results in the K-TDT were indicative of JC's current problems that he was facing especially in expressing himself or in his social interaction with others. He also felt socially awkward with others.

Table AM4. Results of K-TDT

\begin{tabular}{ll}
\hline Items & Interpretation \\
\hline Tree overall & Curvy: indicative of being fragile and sensitive \\
Chioma/Canopy & Chioma refers to the interaction with the physical and external world. \\
& Curvy: indicative of being fragile and sensitive; yearning for protection, \\
& especially when in distress (Koch, 1952). \\
& Branches refer to the drawer's psyche. \\
Branches & Absence of branches, indicative of having difficulty to express oneself in \\
& front of others and not easy for the person to communicate with others \\
& and/or develop relationship; suggestive of unsocial behavior or bohemian \\
& disposition Bohemian disposition means socially unconventional in the way \\
& of doing a given task or handling an issue/task (Koch, 1952). \\
& No clear leaves drawn indicating a lack of inner strength (Koch, 1952). \\
& Trunk is often associated with inner and emotional world. There is an empty \\
knothole drawn (26/3/2019) but a darkened knothole was drawn on \\
another tree drawing (25/5/2019) suggesting a significant unpleasant \\
episode encountered previously. \\
Absence of or shallow roots: indicative of a feeling of exclusion; it could also \\
mean uncertainty and anxiety; suggestive of a lack of emotional and \\
personal ability (Betty G, 2018). \\
Roots
\end{tabular}

\subsubsection{Block V-Cognitive Behavioral Abilities \& Skills}

Block $\mathrm{V}$ focuses more on academic or educational attainments, which include higher levels of cognition, involving word knowledge (i.e., active and passive vocabularies), general knowledge, ability to count and perform operational functions involving numbers and ability to carry out activities using both verbal and nonverbal reasoning skills. Most of the assessment tools are academic attainment 
measures, such as Neale Analysis of Reading Ability- $3^{\text {rd }}$ Edition, Schonell Graded Reading and Spelling Tests and Word Recognition Test.

\section{Primary Measure: Comprehensive} Receptive and Expressive Vocabulary Test$2^{\text {nd }}$ Edition (CREVT-2)

The Comprehensive Receptive and Expressive Vocabulary Test-Second Edition is a norm-referenced instrument designed to assess receptive vocabulary for individuals aged 4-0 through 89-11 and expressive vocabulary for those aged 5-0 through 89-11. CREVT-2 includes a combination of items from the original CREVT, which was designed for children, and the CREVT-A, which was developed for adults. It combines receptive and expressive vocabulary assessment into one instrument. The CREVT-2 has two subtests. The results of the subtests can be combined to form an overall General Vocabulary Index. Here is a brief description of each of the 2 subtests and the General Vocabulary Index:

1. The format of the 76-item Receptive Vocabulary subtest is a variation of the familiar "point-to-the-picture-of-the-wordI-say" technique featuring the unique use of thematic full-color photographs.
2. The Expressive Vocabulary subtest uses the "define-the-word-I-say" format the most popular and precise way to measure expressive vocabulary.

3. The General Vocabulary Index (GVI) is comprised of the Receptive and Expressive Vocabulary subtests. It represents overall ability in the area of oral vocabulary.

JC's GVI was 45 at less than 1\%ile rank with an age equivalent of 9 years 4 months computed from his [(GVI x CA $\div 100]$. His RV Age $<$ EV Age by a significant difference of 15 months.

Before JC is able to use a word correctly and fully, he has to know quite a bit about it, especially its meaning and usage. An important distinction exists, therefore, concerning the words that JC might have in mind. To capture this distinction, Benjamin and Crow (2012) use the terms receptive and productive to differentiate the two types of word knowledge: The former refers to an individual in receptive control of the words that $\mathrm{s} / \mathrm{he}$ understands when s/he hears them or read them; and the latter refers to the individual in productive control of the words that $\mathrm{s} /$ he uses to express him/herself, in speech or in writing.

Table PM5. Results of CREVT-2

\begin{tabular}{lllll}
\hline Subtests & $\begin{array}{l}\text { Raw } \\
\text { Score }\end{array}$ & $\begin{array}{l}\text { Standard } \\
\text { Score }\end{array}$ & $\begin{array}{l}\text { Percentile } \\
\text { Rank }\end{array}$ & Age Equivalent \\
\hline Receptive Vocabulary (RV) & 21 & $<54$ & $<1 \%$ ile & $5: 09$ \\
Expressive Vocabulary (EV) & 9 & $<54$ & $<1 \%$ ile & $7: 00$ \\
\hline General Vocabulary Index (GVI) & -- & 45 & $<1 \%$ ile & $9: 04$ \\
\hline
\end{tabular}

In most cases, an individual's receptive vocabulary is often much larger than his productive vocabulary. In fact, almost every literate adult has a much larger receptive word knowledge. However, in JC's case, his receptive word knowledge is significantly weaker than his expressive word knowledge. This is quite common among individuals with ASD.

As a result, JC scored below an age equivalent of 9 years 4 months (or General 
Vocabulary Index of 45) on the CREVT-2. This result indicated the presence of semantic (meaning) problems at the word level for JC. The semantic knowledge consists of the following two main areas:

1. Logical semantic knowledge that is concerned with matters, such as sense and reference, and presupposition and implication; and

2. Lexical semantic knowledge that is concerned with the analysis of word meanings and relations between them.

With this aspect of language impaired, JC has been noted to continue having a huge challenge in understanding the nature and use of words in both reading comprehension and written expression. In fact, the CREVT-2 results also indicated JC's severely impaired semantic processing (see Collins \& Loftus, 1975 , for detail), both in terms of convergent and divergent semantic processing. Hence, this resulted in his display of difficulties in understanding as well as expressing himself in any conversation or dialogue with others.

\subsection{Level 3-Vocational Assessment and Evaluation}

At this level, vocational assessment has been administered in order to decide on the kind of job training and career options that are appropriate to JC. This is primarily based on (1) aptitudes (2) interests (3) abilities and skill (Camulli \& Xie, 2019). The information obtained from these assessments would help to identify vocational strengths, needs and career potential. Such assessments will also help to evaluate the degree of employability for the YASN and thus match with the employment of the YASN's chosen field.
Primary Measure: World Health Organization Disability Assessment Schedule-Version 2 (WHODAS-2.0)

The World Health Organization Disability Assessment Schedule-Version 2 (WHODAS-2.0) is a generic assessment instrument for health and disability. It provides standardized disability levels and profiles and is applicable across cultures, in all adult populations. It is directly linked at the level of the concepts to the International Classification of Functioning, Disability and Health (ICF, 2007).

The WHODAS-2.0 covers the following six domains of functioning:

1. Cognition - understanding \& communicating

2. Mobility - moving \& getting around

3. Self-care - hygiene, dressing, eating \& staying alone

4. Getting along - interacting with other people

5. Life activities - domestic responsibilities, leisure, work \& school

6. Participation - joining in community activities

In JC's case, based on his condition over the last 20 days, the WHODAS-2.0 questionnaire was proxy-administered and/or completed by JC's family helper who has been taking care of him at least a decade. Currently, JC no longer attended any mainstream, special or alternati2e school. Hence, items D5.5-D5.9 were not required to be completed.

Table PM6. Results of WHODAS-2.0

\begin{tabular}{lllll}
\hline Sections & Score & Comments & & \\
\hline Cognition & $33.33 \%$ & None=2; Mild=1; $\quad$ Moderate=2; & Severe=1;
\end{tabular}


Vol 3 Iss 1 Year 2020

\begin{tabular}{|c|c|c|c|c|}
\hline Mobility & $5 \%$ & $\begin{array}{l}\text { None }=4 ; \quad \text { Mild }=1 ; \\
\text { Extreme/Can't do=0 }\end{array}$ & Moderate $=0$ & Severe $=0$; \\
\hline Self-care & $12.5 \%$ & $\begin{array}{l}\text { None }=2 ; \quad \text { Mild }=2 ; \\
\text { Extreme/Can't do=0 }\end{array}$ & Moderate $=0$ & Severe $=0$; \\
\hline Getting along & $65 \%$ & $\begin{array}{l}\text { None }=0 ; \quad \text { Mild }=0 ; \\
\text { Extreme/Can't do=1 }\end{array}$ & Moderate=3; & Severe $=1$; \\
\hline Life activities & $12.5 \%$ & $\begin{array}{l}\text { None }=4 ; \quad \text { Mild }=4 ; \\
\text { Extreme/Can't do=0 }\end{array}$ & Moderate $=0$; & Severe $=0$; \\
\hline Participation & $62.5 \%$ & $\begin{array}{l}\text { None }=0 ; \quad \text { Mild }=2 ; \\
\text { Extreme/Can't do=3 }\end{array}$ & Moderate=3; & Severe $=0$; \\
\hline Overall Score & 31.81 & -- & & \\
\hline Population \%ile & 88.35 & Significantly high for & culty/problem & \\
\hline
\end{tabular}

Chong Lee WONG/2020

None $=4 ; \quad$ Mild $=1 ; \quad$ Moderate $=0 ; \quad$ Severe $=0$

None $=2 ; \quad$ Mild $=2 ; \quad$ Moderate $=0 ; \quad$ Severe $=0$$$
\text { Extreme/Can't do=0 }
$$

None $=0 ; \quad$ Mild $=0 ; \quad$ Moderate $=3 ; \quad$ Severe $=1$;
Among the six domains, JC's health conditions with problems were found in getting along with others (65\%) and participation $(62.5 \%)$ with an overall score of $31.81 \%$ at the population percentile rank of 88.35\%ile. JC would still need close supervision and/or guidance under his case manager, vocational trainer or job coach

\section{Primary Measure: Functional Assessment Screening Tool (FAST)}

The Functional Assessment Screening Tool (FAST) is designed to identify a number of factors that may influence the occurrence of problem behaviors. It is administered only as an initial screening tool and as part of a comprehensive functional assessment or analysis of problem behavior. It is divided into two main parts:

Part 1: For those with behavior problem consisting of either self-injurious behavior or repetitive stereotyped behaviors; and
Part 2: For those with behavior problem consisting of aggression or some other form of socially disruptive behaviors (e.g., property destruction or tantrum). In JC's case, the FAST was proxy-administered and completed by his mother.

In FAST, the term "social reinforcement" refers to a positive interpersonal stimulus (e.g., verbal praise, smile, touch or a sign of approval) while its negative form is social punishment. According to Cherry (2018), "[S]ocial reinforcement refers to reinforcers such as smiles, acceptance, praise, acclaim, and attention from other people. In some cases, simply being in the presence of other people can serve as a natural social reinforcement" (para.1). The other term, "automatic reinforcement", is nonsocial in nature and it has to do with selfstimulatory or self-injurious behavior. "nonsocial reinforcement, therefore, is more narrowly confined to unconditioned physiological and physical stimuli" (p.99).

Table PM7. Results of FAST

\begin{tabular}{lcccc}
\hline \multirow{2}{*}{ Maintaining Variable } & \multicolumn{2}{c}{ "Yes" Items } & \multirow{2}{*}{ “No" Items } & $\begin{array}{c}\text { Score for } \\
\text { "Yes" }\end{array}$ \\
\cline { 2 - 3 } & Part 1 & Part 2 & & \\
\hline Social Reinforcement (Attention) & 1,2 & 5,7 & $3,4,6,8$ & $50 \%$
\end{tabular}


Social Reinforcement (Access to Specific Activities/Items)
1,2
$9,10,12$,
3,11
$75 \%$
$1,2 \quad 17,18$
$3,14,15$, 16
$50 \%$

Social Reinforcement (Escape)

Average Percentage Score for Social

Reinforcement

$58.33 \%$

Automatic Reinforcement (Sensory Stimulation)

19,20 ,

23

$21,22,24$

$50 \%$

Automatic Reinforcement (Pain Attenuation)

$--\quad 19,20$

$24,25,26$,

27

$33 \%$

Average Percentage score for Automatic

Reinforcement

JC scored an average percentage of "yes" (with problem) is $58.33 \%$ for his poor social reinforcement and an average percentage of "yes" (with problem) is $41.5 \%$ for his poor automatic/nonsocial reinforcement. His highest percentage of "yes" at $75 \%$ for the section on social reinforcement (access to specific activities/items). Such problem behavior (including aggression, selfinjurious behavior [SIB], etc.) have been shown to be maintained more often by social reinforcement (Iwata et al., 1994; Marcus, Vollmer, Swanson, Roane, \& Ringdahl, 2001). On the other hand, JC's stereotyped repetitive behavior was likely to be maintained by automatic reinforcement (Piazza, Adelinis, Hanley, Goh, \& Delia, 2000; Rapp, Miltenberger, Galensky, Ellingson, \& Long, 1999; Vollmer, Marcus, \& LeBlanc, 1994). There was nothing reported of self-injurious behavior noted or observed in JC's current autistic condition.
Primary Measure: Reading-Free Vocational Interest Inventory-2 ${ }^{\text {nd }}$ Edition (RF-VII-2)

The Reading-Free Vocational Interest Inventory-2 ${ }^{\text {nd }}$ Edition makes use of pictures of individuals engaged in different occupations and does not require reading comprehension or written language skills. It consists of a series of 55 sets of three drawings each, depicting different job tasks. An individual is asked to mark the one occupational activity he or she most prefers in each set of pictures. Responses are keyed to yield scores in eleven interest areas and five clusters. A Cluster Quotient is obtained for each examinee from a combination of related interest area scores. The interest categories are: Animal Care, Automotive, Building Trades, Clerical, Food Service, Horticulture, Housekeeping, Laundry Service, Materials Handling, Patient Care, and Personal Service. The clusters are: Mechanical, Outdoor, Mechanical/Outdoor, Clerical/Personal Care, and Food Service/Handling Operations.

Table PM8-A. Results of R-FVII-2

\begin{tabular}{lllll}
\hline Interest Area/Domain & Raw Score & T-Score & Percentile & Rating \\
\hline Automotive (Auto) & 5 & 38 & $12 \%$ ile & Below Average \\
Building Trades (B-Tr) & 7 & 40 & $16 \%$ ile & Below Average
\end{tabular}




$\begin{array}{lllll}\text { Clerical (Cl) } & 3 & 47 & 38 \% \text { ile } & \text { Average } \\ \text { Animal Care (An Cr) } & 9 & 57 & 75 \% \text { ile } & \text { Average } \\ \text { Food Service (FS) } & 9 & 58 & 79 \% \text { ile } & \text { Above Average } \\ \text { Patient Care (P Cr) } & 3 & 53 & 62 \% \text { ile } & \text { Average } \\ \text { Horticulture (Hort) } & 7 & 52 & 58 \% \text { ile } & \text { Average } \\ \text { Housekeeping (Hsk) } & 10 & 51 & 54 \% \text { ile } & \text { Average } \\ \text { Personal Service (P Sv) } & 7 & 57 & 75 \% \text { ile } & \text { Average } \\ \text { Laundry Service (Ly) } & 9 & 65 & 93 \% \text { ile } & \text { High } \\ \text { Materials Handling (M Hg) } & 8 & 56 & 73 \% \text { ile } & \text { Average }\end{array}$

Table PM8-B. Cluster Scores of R-FVII-2

\begin{tabular}{lllll}
\hline Cluster & Raw Score & Cluster Score & Percentile & Rating \\
\hline Mechanical (M) & 12 & 84 & $14 \%$ ile & $\begin{array}{l}\text { Below } \\
\text { Average }\end{array}$ \\
Outdoor (OD) & 16 & 107 & $68 \%$ ile & Average \\
Mechanical-Outdoor (MOD) & 38 & 96 & $39 \%$ ile & Average \\
$\begin{array}{l}\text { Food Service-Handling Operations } \\
\text { (FSH) }\end{array}$ & 17 & 112 & & \\
& & & $79 \%$ ile & $\begin{array}{l}\text { Above } \\
\text { Average } \\
\text { Clerical-Social Service (CSS) }\end{array}$ \\
\hline
\end{tabular}

JC's highest T-score was 65 at 93\%ile rank (High) for the interest area/domain of Laundry Service (Ly) and that was followed by the next highest T-score of 58 at 79\%ile rank (Above Average) for the interest area/domain of Food Service (FS). JC's parents could help him decide which interest area/domain he wished to pursue for his vocational training and it could be followed up with his vocational evaluation and eventually to design his Individualized Vocational Training Plan (IVTP).

Results from JC's R-FVII-2 Cluster Scores indicated that his vocational preference was Food Service-Handling Operations (FSH). In terms of JC's FS interest, it meant his preference for activities involving the preparation and serving of food, and clean-up tasks in kitchens and dining areas in restaurants, hotels, motels and clubs. Such jobs include server, bus person, salad preparer, baker, car hop, dishwasher, short order cook, counter person, soda fountain clerk, food try assembler, and kitchen helper.

The Food-Service-Handling Operations (FSH) interest meant JC's preference for job tasks characterized by manual or physical work and the delivery of personal services to recipients that would require little or no physical contact. The type of personal service emphasized by the cluster includes occupations concerned with the preparation and serving of food and beverages and related activities. Such jobs include stevedore, grocery packer or bagger, fork life operator, diary products driver, supermarket stock clerk, glass 
washer and carrier, hot food packer, kitchen helper, lunch truck driver, meat cutter, vending machine attendant, wine-and-beer truck driver, fast foods cook, and server are the many jobs in this field. In order to ensure that JC was able to relate his interest and abilities to his career choices, a supplementary test was called for in order to get clarification in this aspect. The Career Interest InventoryPictorial (CII-P) Test attempts to link JC's career interest to related courses that could help him prepare professionally.
Supplementary Measure: Career Interest Inventory-Pictorial (CII-P)

The CII-P is adapted from the Holland Occupational Themes based on the theory of personality that focuses on career and vocational choice. It is designed for use pictorially with individuals with non-verbal autistic condition or low intellectual capacity. The CII-P groups people on the basis of their suitability for six different categories of occupations. The six types yield the RIASEC acronym, by which the theory is also commonly known.

Table SM4. Results of CII-P

\begin{tabular}{llllll}
\hline Categories & Tasks & & Scores & Percentage & Comments \\
\hline Realistic (R) & Doer & Things & 4 & $67 \%$ & \\
R-I & -- & Sociability & $4+4$ & $67 \%$ & \\
Investigative (I) & Thinker & -- & 4 & $67 \%$ & No specific or \\
Artistic (A) & Creator & Conformity & 4 & $67 \%$ & clear choice \\
Social (S) & Helper & People & 4 & $67 \%$ & made by the \\
S-E & -- & Sociability & $4+2$ & $50 \%$ & client. \\
Enterprising (E) & Persuader & -- & 2 & $33 \%$ & \\
Conventional (C) & Organizer & Conformity & 4 & $67 \%$ & \\
\hline
\end{tabular}

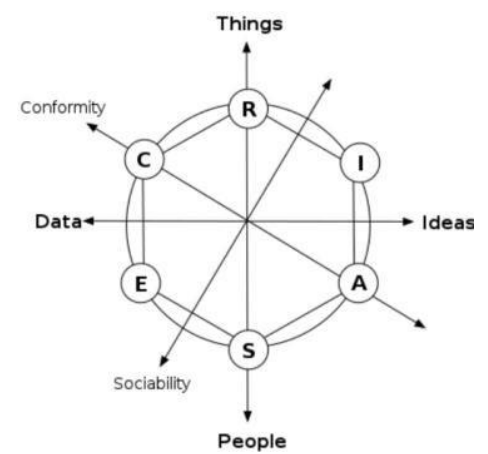

Figure 1. The Hexagon of Holland Codes

The theory was developed by John L. Holland (b.1919-d.2008), an American psychologist and Professor Emeritus of Sociology at Johns Hopkins University, over the course of his career, starting in the 1950s. The typology has come to dominate the field of career counseling and has been incorporated into most of the assessments used in the field of career guidance and counseling.

The aim of the CII-P is to help the assessor to find out the client's interests and abilities to career choices.

The results did not indicate a clear career choice made by JC in the CII-P 
administration and hence, it was difficult to use the hexagon of the Holland Codes to determine JC's personality fit for the kind of career choice most appropriate for him.

However, the results suggested that JC could be less suited for career choice related to social-enterprising type (i.e., involving helperpersuader tasks). Also, he is certainly not one with enterprising (E) personality to begin with.

\section{Primary Measure: Vocational Assessment \& Planning (VAP)}

Functional Vocational Assessment (FVA), also known as Functional Vocational Evaluation (FVE), is an in-depth look at the career and vocational aspects of a student's transition. The FVA/FVE covers the transition service which a vocational training center or school can offer. Often, the student might be observed in a work activity to measure aptitude by his/her job coach or vocational trainer. This service provides specific data so that educational objectives for communitybased work and vocational education can be designed.

The Functional Vocational Assessment (scoring on the 5-point Likert rating scale) was completed by the family helper as a proxy since JC's mother was not available at the time of assessment.

\begin{tabular}{|c|c|c|}
\hline Section & Factors & Comments \\
\hline Internal & 1. Initiative & 3; Follow instructions \\
\hline \multirow[t]{9}{*}{ Work Skills } & 2. Attention to task and completion & 2; Prompts required \\
\hline & 3. Adapting to change (ability to & 3; Able to adapt \\
\hline & transition) & 3; Sometimes required \\
\hline & 4. Reinforcement needs & 3; Sometimes does \\
\hline & 5. Evaluates completed task & \\
\hline & Sub-total score: & 14 \\
\hline & Percentage: & $56 \%$ \\
\hline & Mean score: & 2.8 \\
\hline & Descriptor: & Average internal work skills \\
\hline \multirow[t]{3}{*}{ Social Skills } & 1. Social interaction & 1; Little, if any interaction \\
\hline & 2. Behavior & $\begin{array}{l}\text { 2; Occasional unusual behaviors } \\
\text { (may display agitation at times) }\end{array}$ \\
\hline & 3. Grooming/hygiene & $\begin{array}{l}\text { Positive hygiene but still needs } \\
\text { to improve (No score for this } \\
\text { item) }\end{array}$ \\
\hline
\end{tabular}

\begin{tabular}{lll}
\hline \multicolumn{2}{l}{ Table Continued } & \\
\hline & Sub-total score: & 3 \\
& Percentage: & $30 \%$ \\
& Mean: & 1.5 \\
& Descriptor; & Poor social skills \\
\hline Tasks & Cleaning the toilet, sweeping the floor, & -- \\
performed & baking, mopping the floor, general cleaning & \\
\hline Specific & Lack of conversation & -- \\
needs & & \\
\hline
\end{tabular}




\begin{tabular}{|c|c|c|}
\hline Work-related & 1. Lifting strength & 5; Excellent - more than $23 \mathrm{~kg}$ \\
\hline Skills & 2. Endurance & 5; Can work a full day \\
\hline & 3. Physical mobility & 5; Excellent - full physical \\
\hline & 4. Handling criticism & capabilities \\
\hline & & 4; Can accept criticism \& makes \\
\hline & 5. Acts and speaks appropriately & changes \\
\hline & 6. Orientation & 4; Frequently \\
\hline & & 5; Can work in/on entire \\
\hline & 7. Discrimination skills & building or grounds \\
\hline & & 4; Can distinguish between \\
\hline & 8. Time awareness & work tools \& supplies \\
\hline & 9. Functional reading & 3; Sometimes \\
\hline & & 5 ; He is a fluent reader (but \\
\hline & 10. Functional math & with no understanding) \\
\hline & & 4; Can understand most math \\
\hline & 11. Availability for work & functions \\
\hline & & Daytime/Part-time \\
\hline & Sub-total score: & 44 \\
\hline & Percentage: & $88 \%$ \\
\hline & Mean: & 4.4 \\
\hline & Descriptor: & High occupational functionality \\
\hline Transport & $\begin{array}{l}\text { - Mode: Take public transportation } \\
\text { - Able to take public transport on his } \\
\text { own }\end{array}$ & $\begin{array}{l}\text { Is mobile and can travel on } \\
\text { public transport once taught } \\
\text { how to do so. }\end{array}$ \\
\hline Strength & $\begin{array}{l}\text { - } \quad \text { Good strength } \\
\text { - } \quad \text { Can work } 8 \text { hours (can endure) } \\
\text { - } \quad \text { Can focus on a job till it is done }\end{array}$ & $\begin{array}{l}\text { Diligent and can stay focused } \\
\text { until a given task is completed. }\end{array}$ \\
\hline $\begin{array}{l}\text { Areas } \\
\text { needing } \\
\text { improvement }\end{array}$ & $\begin{array}{l}\text { - Needs to converse, ask questions } \\
\text { - Depending on situation, may lose } \\
\text { temper }\end{array}$ & $\begin{array}{l}\text { Is still unable to hold a } \\
\text { conversation with others due to } \\
\text { his impaired semantic } \\
\text { processing. }\end{array}$ \\
\hline
\end{tabular}

Based on the input provided by the family's helper as a proxy, JC was said to exhibit average internal work skills but poor social skills. Possessing a high level of occupational functionality and with some monitoring or supervision, the Functional Assessment Rating Scale (FARS) was carried out with JC. The test is described briefly below.

\section{Supplementary Measure: Functional Assessment Rating Scales (FARS)}

The Functional Assessment Rating Scales FARS for adult behavioral health functional assessment are ways of documenting and standardizing impressions from clinical evaluations or mental status exams that assess cognitive, social and role functioning.

The purpose of this Functional Vocational Evaluation is to arrange JC for appropriate vocational training in his interest area for his career development and employability. The rating scores are as follows:

$1=$ No problem, $2=$ Less than slight

$3=$ Slight problem, 4 = Slight to moderate

$5=$ Moderate problem, $6=$ Moderate to severe 
$7=$ Severe problem, $8=$ Severe to extreme

$9=$ Extreme problem

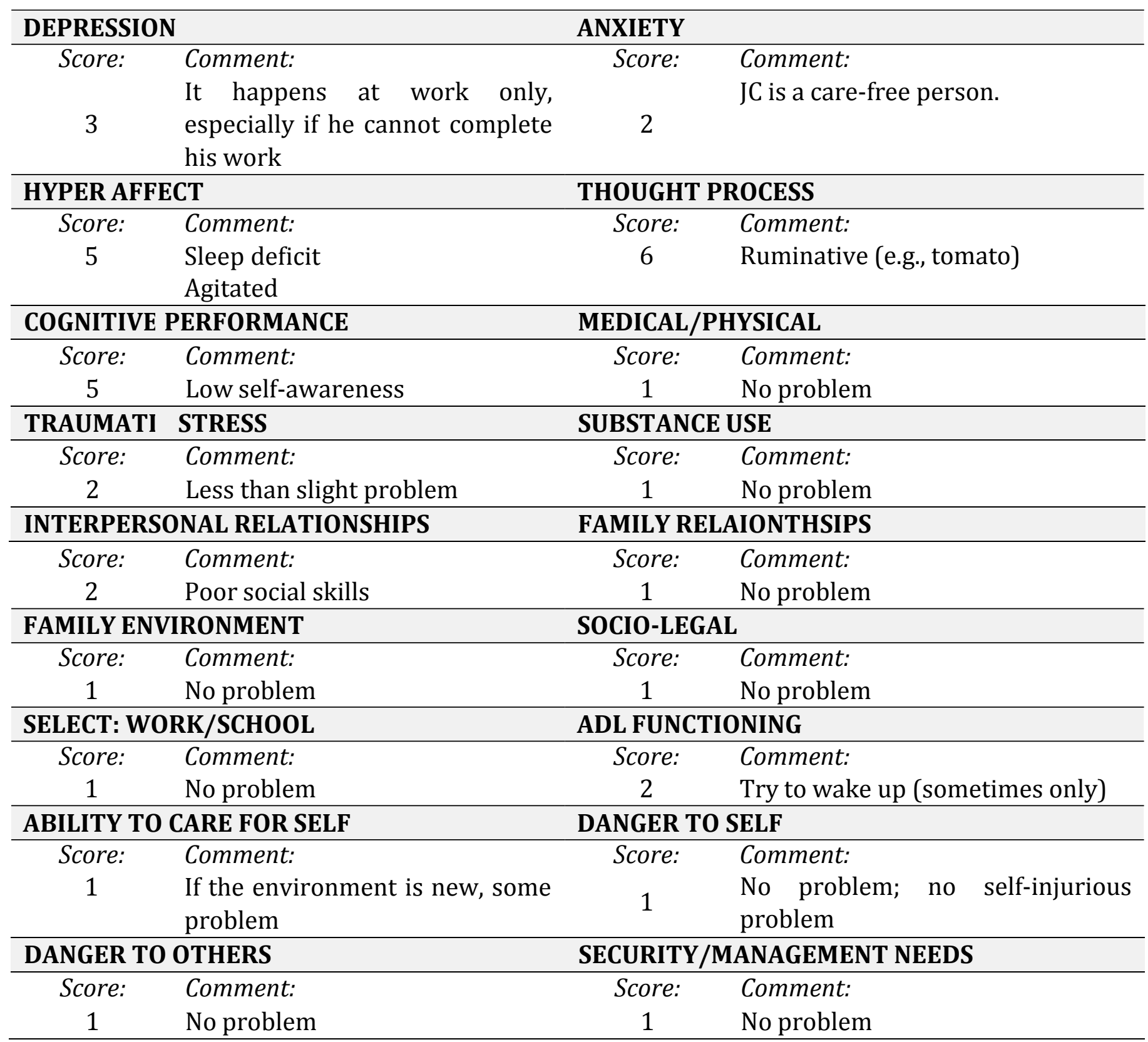

There are three areas with problem severity and they are: (a) hyper affect; (b) cognitive performance; and (c) thought process. For the first area of problem concerning hyper affect, an additional measure/assessment - the Emotional Hyperarousal Questionnaire (EHQ) - was conducted but there is no evidence of the problem. For the second area of problem concerning poor cognitive performance, it is best explained by JC's intellectual/cognitive disability as shown in GAMA and DaP-IQ results and borderline intellectual/cognitive functioning as indicated in TONI-3 results. Finally, the third area of problem concerning thought process, especially rumination, is a typical problem displayed by an individual with autism spectrum disorder. 


\section{Discussion of the Assessment Results}

JC has been found to manifest low GAMA IQ of 65 (at 1\%ile rank) and an impaired cognitive maturity with a DaP-IQ of 67 (at 1\%ile rank), i.e., cognitive impairment. His TONI-3 IQ of 76 (at 5\%ile rank) places him in the range of borderline intellectual/cognitive functioning.

JC also displayed an extremely low functioning Adaptive Behavior (ABDS) profile with a composite score of 35 (at $<1 \%$ ile rank; $\mathrm{SEM}=3$ ) in the pattern of Practical > Communication $>$ Social. This is the autism profile of adaptive behavior as mentioned earlier (Saulnier \& Klaiman, 2018). In addition, "[G]iven that adaptive and cognitive delays make up the diagnostic criteria for intellectual disability (ID), it is not surprising that these two constructs would be historically associated with autism" (Saulnier \& Klaiman, 2018, p.80).

From the ABDS results, JC was found to have deficits in his adaptive behavior skills. This means that JC displayed social incompetence due to developmental delay including intellectual disability. The term social competence refers to "the ability to demonstrate personal independence and social responsibility in everyday contexts" (Saulnier \& Klaiman, 2018, p.4-5) or "may be defined as a functional composite of human traits which sub-serves social usefulness as reflected in self-sufficiency and in service of others" (Doll, 1953, p.2).

In addition, JC's SP-CQ Factor \#2 result of a "probable" problem of being emotionally reactive points to the high chance of having emotional hyperarousal (Dodson, 2019). rejection sensitivity dysphoria since the result on the Emotional \& Behavior Responses was probable. The condition of emotional reactivity refers to what Dodson (2019) has termed as emotional hyperarousal. However, the EHQ results failed to show any evidence of the emotional problem. Among the 14 SP-CQ sections, the section on Emotional/Social Responses under the Domain 3-Emotional \& Behavioral Responses indicated the presence of social-emotional problems in JC. This has been further supported by JC's poor performance in the COM and SI subtests of GARS-2 as well as the lowest score in the Social Domain (SD) among the three ABDS domains.

JC's SP-CQ results also indicated that he might display the following probable behavioral problems

1. Emotional hyperarousal due to Factor \#2 and therefore, can be emotionally sensitive and reactive to verbal remarks or physical actions that he interprets as negative. This emotional hyperarousal also leads to condition of rejection sensitivity dysmorphia. However, additional measures - RSDS and EHQ - were administered later to rule out both conditions;

2. Deficits in movement kinematics due to Factor \#3-low endurance/tone. Movement kinematics plays an important role in social cognitive function involving action perception, prediction and interpretation crucial to social communication. Poor movement kinematics indirectly also affects his social cognition (Cook, 2016), which focuses on how he processes, stores, and applies information about other people and social situations. In other words, social cognition focuses on the role that cognitive processes play in social interactions (Park et al., 2015). Hence, with poor SP-CQ Factor \#3, JC's social communication is strongly affected and this finding is also supported by his poor performance in the GARS-2 subtests COM and SI as well as poor result noted in the ABDS Social Domain.

3. Hypo-sensitivity due to Factor \#6-poor registration is applied "to those who do not absorb, or register, all of the input entering their body, and they are therefore 'missing out' on crucial information from their own 
body and the environment, which is used to make adaptive responses and learn" (Langer, 2019, para.2).

JC's GARS-2 results showed that he has autism with an AI of 100 (at 50\%ile rank; $S E M=4$ ) and the following GARS-2 pattern: $\mathrm{COM}>\mathrm{SI}>\mathrm{SB}$, where COM scaled score being the most severe and SB scaled score being the least severe. As already mentioned earlier above, because of his poor communication ability, JC is unable to socialize well or adequately with others and may encounter problems in interacting with his peers or significant others, who do not understand his condition or personality.

In addition, the supplementary measure ESQ results indicated that JC to display (i) weak or poor metacognition, (ii) lacking flexibility, (iii) poor planning/prioritization and (iv) low stress tolerance that causes JC to feel anxious or stressed about what he is doing and the contextual feedback from his immediate environment (e.g., his training workplace). In other words, such anomalous behavioral responses are typical of an individual with autism and/or attention deficit/hyperactivity disorder. Extra effort must be taken by his workplace supervisor as well as his job coach to know and understand his ES profile in order to maximize his potential as a worker/employee.

JC's performance in the CREVT-2 showed that both his RV and EV have a derivative quotient of $<54$ (less than 1\%ile rank) and his General Vocabulary Index (GVI) of 45 (less than 1\%ile rank) is the typical profile of an individual with non-verbal lowfunctioning autism whose verbal abilities are extremely poor or limited. This could be the result of his severely impaired convergent and divergent semantic processing. Hence, he did show problem in comprehending complex verbal instructions as well as lexically dense reading texts. Results from B-VAQ also ruled out cognitive and/or affective alexithymia, which is a personality construct characterized by the subclinical inability to identify and describe emotions in the self and that was more likely due to JC's impaired semantic processing as indicated in his results of CREVT-2. The core characteristics of alexithymia are marked dysfunction in emotional awareness, social attachment, and interpersonal relating (FeldmanHall, Dalgleish, \& Mobbs, 2013) - all these main traits were confirmed by other primary measures in the vocational assessment and evaluation

\section{Conclusion}

From the findings of the numerous assessments done, JC's GAMA and TONI-3 scores put him under the category as someone who is educable, can learn to take care of himself and even be employable in routinized jobs but need constant handholding with explicit instructions so as to ensure he is able get the work done. His Sensory Profile does indicate that there are "probable" challenges that he would face especially in the emotional management and ability to self-express. Plenty of assurances and encouragement would perhaps reduce the severity of his moods and thus stabilize in his ability to work well.

In terms of JC's current functional vocational profile, he exhibits average internal work skills, possesses a high level of occupational functionality and is most suited for the food service-handling operations in his vocational interest and/or career development. However, JC still needs close supervision and/or guidance by his case manager, vocational trainer and/or job coach at the workplace. His main problems and difficulties lie in his low cognitive performance, rumination and poor social skills with emotional challenges at times, especially when he becomes stressed by sudden changes to his work routine. Proper transition is required and is a must to be included in the design of his Vocational Treatment Plan (VTP) 
and it has to be followed up by his case manager, vocational trainer or job coach.

\section{References}

Wong, C. (2017). APPLICATION OF THE TRIPLE-E EMPLOYMENT FRAMEWORK TO DECIDE ON THE EMPLOYABILITY OF YOUNG ADULTS WITH SPECIAL NEEDS. European Journal of Special Education Research, 2(4), pp.35-45.

Horne, Richard. "Vocational Assessment: A Guide for Parents and Professionals." NICHCY Transition Summary (1990).

Flanagan, Dawn P., and Kevin S. McGrew. "A cross-battery approach to assessing and interpreting cognitive abilities: Narrowing the gap between practice and cognitive science." (1997). In D.P. Flanagan \& P.L. Harrison (Eds). Contemporary intellectual assessment: Theories, tests, and issues. The Guilford Press, (pp. 314-325). New York, NY: The Guilford Press.

Flanagan, D. P., Ortiz, S. O., \& Alfonso, V. C. (2007). Use of the cross-battery approach in the assessment of diverse individuals. In A. S. Kaufman \& N. L. Kaufman (Eds.), Essentials of cross-battery assessment (2 ${ }^{\text {nd }}$ Ed.) (pp.146-205). New York, NY: John Wiley \& Sons.

Chia, K. H. "Educating the whole child in a child with special needs: What we know and understand and what we can do." ASCD Review 14 (2008): 25-31.

Lindemann, J. E., \& Matarazzo, J. D. (1990). Assessment of adult intelligence. In J. E. Lindemann \& J. D. Matarazzo (Eds.), Handbook of psychological assessment (2nd ed.) (pp.79-101). New York, NY: Pergamon Press.

Reynolds, C. R., \& Hickman, J.A. (2004). Draw-A-Person Intellectual Ability for Children, Adolescents, and Adults (DAP:IQ) examiners manual. Austin, TX: Pro-ed. Ricci, C (1894)

Siegel, Bryna. The world of the autistic child: Understanding and treating autistic spectrum disorders. Oxford University Press, USA, 1997.

Sattler, J.M. (2001). Assessment of children (4th ed.). San Diego, CA: Jerome Sattler, Publishers, Inc.

Buck, J. N. (1977). The House-tree-person (HTP) manual supplement: Administration and interpretation of the HTP test. (Based on materials used at HTP workshop, Veterans Administration Hospital, Richmond, Virginia, Spring, 1950; together with materials from subsequent workshops). Torrance, CA: Western Psychological Services.

National Information Center for Children \& Youth with Disabilities, (1990). Special services for children and youth with disabilities. Washington, DC: The Author

Dunn, W. (1999). Sensory profile-caregiver questionnaire. San Antonio, TX: Psychological Corporation.

Dodson, W. (2018). Three defining features of ADHD that everyone overlooks. New York, NY: New Hope Media.

W, D. (2019). Rejection Sensitive Dysphoria and ADHD: How to Get Over RSD. [online] ADDitude. Available at: https://www.additudemag.com/rejection-sensitive-dysphoria-and-adhd/. 
Ermer, Julie, and Winnie Dunn. "The Sensory Profile: A discriminant analysis of children with and without disabilities." American Journal of Occupational Therapy 52.4 (1998): 283-290.

L.A, W. (2019). Alexithymia, Empathy, and Autism - Living Autism. [online] Living Autism. Available at: https://livingautism.com/alexithymia-empathy-autism/.

Bermond, Bob, et al. "The Amsterdam Alexithymia Scale: its psychometric values and correlations with other personality traits." Psychotherapy and psychosomatics 68.5 (1999): 241-251.

Cook, Jennifer. "From movement kinematics to social cognition: the case of autism." Philosophical Transactions of the Royal Society B: Biological Sciences 371.1693 (2016): 20150372.

Park, Mina, et al. "The relation between nonverbal IQ and postoperative CI outcomes in cochlear implant users: preliminary result." BioMed research international 2015 (2015).

20. A, L. (2019). 10 Red Flags for Poor Sensory Registration - North Shore Pediatric Therapy. [online] North Shore Pediatric Therapy. Available at: https://www.nspt4kids.com/health-topics-

and-concerns/sensory-processing-disorder/10-red-flags-poor-sensory-registration/.

Saulnier, Celine A., and Cheryl Klaiman. Essentials of Adaptive Behavior Assessment of Neurodevelopmental Disorders. John Wiley \& Sons, 2018.

Baddeley, Alan, and Barbara Wilson. "Frontal amnesia and the dysexecutive syndrome." Brain and cognition 7.2 (1988): 212-230.

M, G. (2020). Tree of Life. [online] Our Paths in the Valley. Available at: https://greenway.typepad.com/green way/2008/03/tree-of-life-1.html.

Koch, Karl. The tree test: The tree drawing test as an aid in psychodiagnosis. Hans Huber, 1952.

Benjamin, Amy, and John T. Crow. Vocabulary at the core: teaching the common core standards. Eye on Education, 2013.

Camulli, Jennifer Erin, and Guohui Xie. "The Employment Continuum: A Framework for Hiring People with Disabilities in Dubai, UAE." Asian Journal of Interdisciplinary Research 2.3 (2019): 56-75.

K, C. (2018). How Does Social Reinforcement Influence Everyday Behaviors?. [online] Verywell Mind. Available at: https://www.verywellmind.com/what-is-social-reinforcement-2795881.

Iwata, Brian A., et al. "Toward a functional analysis of self-injury." Journal of applied behavior analysis 27.2 (1994): 197-209.

Marcus, Bethany A., et al. "An experimental analysis of aggression." Behavior modification 25.2 (2001): 189-213.

Piazza, Cathleen C., et al. "An evaluation of the effects of matched stimuli on behaviors maintained by automatic reinforcement." Journal of Applied Behavior Analysis 33.1 (2000): 13-27.

Rapp, John T., et al. "A functional analysis of hair pulling." Journal of Applied Behavior Analysis 32.3 (1999): 329-337.

Vollmer, Timothy R., Bethany A. Marcus, and Linda LeBlanc. "Treatment of self-injury and hand mouthing following inconclusive functional analyses." Journal of Applied Behavior Analysis 27.2 (1994): 331-344.

E.A, D. (1953). Your child grows up. Vineland Training School. 
FeldmanHall, Oriel, Dean Mobbs, and Tim Dalgleish. "Deconstructing the brain's moral network: dissociable functionality between the temporoparietal junction and ventro-medial prefrontal cortex." Social Cognitive and Affective Neuroscience 9.3 (2014): 297-306

\section{Acknowledgement}

The writer wishes to thank the following people for their kind assistance in the writing of this paper: (1) The family of JC for their kind permission to use the assessment results in this case report for the purpose of sharing with other interested parties; and (2) Dr Guo-Hui Xie for his professional advice and feedback.

Funding: No funding was received for conducting this study.

Conflict of Interest: The Author has no conflicts of interest to declare that they are relevant to the content of this article.

About the License: (C) The author 2020. The text of this article is open access and licensed under a Creative Commons Attribution 4.0 International License 